\title{
The Functions Of Cultural Schemata In The Chinese Reading Comprehension And Reading Time Of College Students In Taiwan
}

Chen-Hong Li, National Penghu University of Science and Technology, Taiwan Shu-Fen Lai, De Lin Institute of Technology, Taiwan

\begin{abstract}
The study examined the effects of cultural familiarity with a text on Chinese students' reading comprehension performance and reading time. In the first phase of the study, participants were required to read a culturally familiar text, write down the time they spent reading the passage, and immediately complete a cloze test without referring back to the culturally-embedded text. In the second phase, they went through the same procedure for a culturally unfamiliar text. Upon completion of the reading tasks, a topic familiarity questionnaire was distributed to them to complete in order to screen out those who were culturally familiar with both reading texts. A survey about their attitudes toward the role that background knowledge played in their reading process was administered to them following the topic familiarity questionnaire. The results showed that the students' reading comprehension performance and reading time were both significantly affected by their familiarity with the target culture. They spent less time on and comprehended better the culturally-embedded text they were familiar with. Analysis of the survey also substantiated the claim that they relied on the facilitative role of background knowledge in reading so as to read in a faster and more efficient way. The findings suggest that a reader's cultural schemata impacts memory, reading comprehension, interpretation and reading time. Pedagogical implications of the study and suggestions for future research are also discussed in the article.
\end{abstract}

Keywords: Cultural Schemata; Reading Comprehension; Reading Time; Schema Theory

\section{INTRODUCTION}

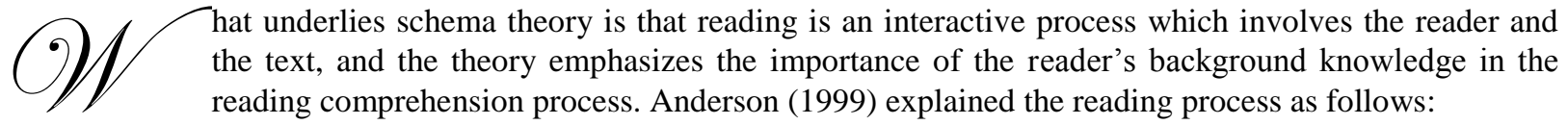

Reading is an active, fluent process which involves the reader and the reading material in building meaning. Meaning does not reside on the printed page....Synergy occurs in reading, which combines the words on the printed page with the reader's background knowledge and experiences. (p. 1)

When reading, people tend to integrate text-driven features (i.e., letter identification and lexical access) and reader-driven features (i.e., activation of prior knowledge and monitoring comprehension) into the reading process in order to see beyond the literal meaning of words (Bernhardt, 1991; Brantmeier, 2004; Harmer, 2001). The crucial role that background knowledge or schema plays in promoting insightful comprehension of the reading text and producing a rich text interpretation is noted in several studies (Carrell, 1983, 1987; Carrell \& Eisterhold, 1983; Erten 
\& Razi, 2009; Johnson, 1981, 1982; Kintsch \& Greene, 1978). In short, activating readers' existing schema, or at least providing them with crucial information about the reading topic in order to help them comprehend and interpret the reading text better, is something that cannot be overlooked in the language classroom.

\section{LITERATURE REVIEW}

Cognitive scientists believe that knowledge is organized around schemata. Schema theory plays an important role in theories of first and second language reading comprehension. Rumelhart (1980) noted, “...a schema theory is basically a theory about knowledge. It is a theory about how knowledge is presented and how that representation facilitates the use of the knowledge in particular ways" (p. 34). From a schema theory perspective, a text itself does not carry any meaning. Rather it gives readers clues that enable them to construct meaning from the knowledge they already possess. As a result, the reading comprehension process is viewed in current models of reading as an active process in which the reader constructs propositional meaning by supplying relevant background knowledge in the comprehension process rather than by simply matching the word to its meaning. Lack of necessary background knowledge about a topic is one of the 'inside-the-head' factors that impede reading comprehension.

A number of research results highlight the critical role that schema theory plays in the reading comprehension process, and a lack of such knowledge may make the prediction and anticipation of the reading content difficult (Carrell, 1983, 1987; Carrell \& Eisterhold, 1983; Johnson, 1981, 1982; Smith, 2004). In order to understand the impact of cultural schema, one type of background knowledge or schema, on reading comprehension, a definition of this term is found in Ketchum (2006) and Yule (1996). Ketchum defined cultural schema as a culturespecific extension of content schema because it refers to the crucial role that a reader needs to fully comprehend a writer's intended meaning. Yule indicated that schemata are developed "in the context of our basic experiences" ( $p$. 87). Alptekin (2006) pointed out that cultural schema, though abstract in nature and independent of the surface forms used in the formation of the text, involves more than a mere literal comprehension of the content of the text. Thus, it suggests that not possessing the appropriate schema or being unable to activate it to allow new experiences and information to be aligned with it leads to an inaccurate representation of the meaning of the reading text.

Several research studies have reported positive effects of cultural familiarity on reading comprehension. To compare the effects of culturally familiar/unfamiliar materials on reading comprehension and interpretation, Pritchard (1990) designed a study in which thirty American and thirty Palauan $11^{\text {th }}$-grade native language readers were selected. Both groups read two articles written in their own language, one with culturally familiar content and the other with culturally unfamiliar content. The results showed that the repertoire of processing strategies used by the Americans was greater than that used by the Palauans, and when reading culturally familiar texts, readers were more likely to establish inter-sentential ties and used their background knowledge for a better comprehension and interpretation of the text.

Similarly, Carrell (1987) contended that a reader's cultural background knowledge influenced interpretation of a text and that the reader's performance on the test was superior when the cultural-familiar texts were presented as opposed to the reader's performance on the cultural-unfamiliar ones. This finding coincides with Johnson's (1982) study on the positive relationship between cultural background knowledge and reading comprehension performance of cultural sensitive materials. In Johnson's study, a higher recall test score on the Halloween topic was found after students participated in a series of Halloween activities.

Johnson (1981) also found that cultural background knowledge plays a more important role in reading comprehension than semantic and syntactic factors do. This point was supported by Carrell and Eisterhold (1983). They argued that when it comes to reading comprehension, too much focus is on the text components (i.e., vocabulary knowledge, syntactic knowledge), not on the reader. They claimed that the reader's contribution, to be more specific, the reader's background knowledge, plays a crucial role in the process of reading comprehension. The results of Erten and Razi (2009) study also acknowledged the facilitative role of background knowledge and cultural familiarity in reading comprehension. The two groups in their study that received the adjusted version of the story scored higher in reading comprehension than the other two groups that were provided with the original version. 
Background knowledge not only aids in decoding new information, but it is also believed to enhance reading rate. When reading, people manage to deal with micro-level linguistic features and macro-level textual analysis. Since our working memory is limited in capacity, too much demand on it could overload the cognitive system, which in turn leads to an inefficient processing of the reading task (Baddeley, 1997; McLaughlin, Rossman $\&$ McLeod, 1983; Pulido, 2003). It has been argued, however, that successful activation of the schemata that readers bring to the reading process can lighten the cognitive load of the working memory (Ellis, 2001; Nassaji, 2002), and thus readers can direct more attention to micro-level features and read the text in a faster and more efficient way.

According to Smith (2004), readers read a familiar passage more rapidly than an unfamiliar one. Smith addressed the importance of the role of pre-existing knowledge in the prediction and anticipation of the text. One consequence of not being able to activate pre-existing knowledge is that the prediction and anticipation powers fail. The short-term memory is overloaded, and the processing of the text takes longer and the reading rate drops.

Investigating the influence of cultural schemata on readers' comprehension process, Steffensen, Joag-dev, and Anderson (1979) worked with two groups of readers, Americans and Indians, reading letters about an American and an Indian wedding. It was demonstrated that when the readers are familiar with cultural norms of the text, they make a better interpretation of the text than when they are not, and they recall more and read faster the text that is related to their mainstream culture.

The positive role of background knowledge organized around schemata in facilitating reading comprehension is acknowledge in many aforementioned research studies; however, research findings suggest that there is still a need to further study the role of background knowledge on the reading comprehension process of different reader populations (Carrel, 1988; Grabe, 1991). Research on Taiwanese college students' Chinese reading comprehension is rare. This study is expected to pique the interest of other Taiwanese researchers in this field. It is hoped that a better understanding of the role of background knowledge in the reading process of Taiwanese college students can be provided, and some pedagogical implications can be illuminated to improve their reading ability. Three questions to be specifically addressed in this study are:

1. Does reading a culturally familiar text vs. reading a culturally unfamiliar text influence the Chinese reading comprehension of college students in Taiwan?

2. Is the reading time of the students affected by their familiarity with the text content?

3. What are students' attitudes and opinions toward the role of background knowledge in their reading comprehension process?

\section{METHOD}

\section{Participants}

A total of 55 students - 21 males and 34 females - in the Department of Teaching Chinese as a Second Language at a northern university in Taiwan were recruited for the study. They were sophomores whose native language (L1) is Mandarin Chinese. As indicated by the information given in the topic familiarity questionnaire (see below), those who were culturally familiar withy both reading texts were eliminated from the data analysis. Two participants reported that they were familiar with both holidays, and their data collected in the study were eliminated and destroyed. Thus, data collected from the remaining 53 students were used for further statistical analyses.

\section{Design}

This study used a within-subjects design. The independent variable was the reading text content with two levels - culturally familiar and culturally unfamiliar. The dependent variables were the reading time and the reading comprehension score on the cloze test. 


\section{Instruments}

Reading Texts

Two reading passages of nearly equal length written in Mandarin Chinese were prepared by the researchers. One passage, the Dragon Boat Festival, consisted of 1,361 words. The festival is a traditional holiday to the Chinese and it has been celebrated each year on the fifth day of the fifth month on the lunar calendar for thousands of years. This day is well-known to the Chinese. The other reading passage, which was composed of 1,357 words, described an Irish holiday, St. Patrick's Day, and it is presumably an unfamiliar holiday to most people in the east of Asia. The validity of the reading texts was obtained via an expert. An experienced professor of Chinese was asked to evaluate the two passages in terms of their textual structure and readability level. She considered the two reading texts generally equivalent, and the interconnection of ideas was clear to comprehend.

\section{Cloze Test}

In order to test the participants' reading comprehension and recall of the two reading texts, a cloze test with twenty key words deleted and replaced by blanks was constructed by the researchers for each of the reading texts. This technique is considered as an effective tool for evaluating comprehension and recall by many scholars (Eskey, 1973; Hewett, 1985; Schulz, 1984). The cloze tests were scored by the researchers using the exact-word scoring method (Meyer, Talbot, \& Florencio, 1999). Five points were given to each word correctly recalled with a full score of 100 for each of the reading passages.

\section{Topic Familiarity Questionnaire}

A topic familiarity questionnaire was developed to tap the participants' familiarity with the two holidays using a Likert Scale with a range from 5 to 1: (5) know a lot about the holiday, (4) know quite a bit about the holiday, (3) know something about the holiday, (2) know very little about the holiday, and (1) know nothing about the holiday. Participants whose rating on both of the holidays reached above 2 were thus excluded from the data analysis.

\section{Attitude Survey}

An attitude survey containing six statements about the role of background knowledge in reading comprehension was developed. Using either a 'Yes' or a 'No', participants were asked to respond to each of the six items in the questionnaire by indicating if they agreed or disagreed with each statement.

\section{Experimental Procedure}

The experiment was about 50 minutes long. A trained co-investigator, Ms. Wang, was responsible for administering the test to those voluntary participants. In the first 20-minute session, they were required to read the culturally familiar text, write down the time they spent reading the passage by looking at a digital timer in the front of the classroom, and then immediately answer the cloze test without referring back to the reading text. In the second session, they went through the same procedure for the culturally unfamiliar text. A topic familiarity questionnaire was distributed to them to complete at the end of the test to screen out those who were culturally familiar with both reading texts. In addition, they were asked to complete the attitude survey about the role of background knowledge in their reading comprehension process. There was no time limit in answering the cloze tests or completing the questionnaires.

\section{Data Analysis}

The data aggregated in this study were analyzed by using descriptive statistical procedures and a pairedsamples $t$-test to examine whether there were any significant differences in the reading comprehension scores and 
the reading time between the two passages. Regarding the analysis of the survey, a chi-square test was used to examine whether the number of responses at the two levels, positive and negative, was equally distributed for each of the six statements in the questionnaire.

\section{RESULTS}

The results obtained for the three research questions addressed in the study are reported in Tables 1-3. Table 1 shows the means of the score on the cloze tests and the means of reading time in seconds for each of the two reading passages. As shown in Table 1, the mean reading score on the cloze test of the familiar text $(M=79.62, S . D$. $=14.51)$ was higher than that of the unfamiliar text $(M=43.49$, S.D. $=19.82)$; the mean reading time spent on the familiar text $(M=262.36, S . D .=146.08)$ was lower than that on the unfamiliar text $(M=300.19, S . D .=114.68)$. It is clear that the participants' degree of familiarity with a text was inversely related to their amount of time spent on the text. The results of the paired-samples $t$-test in Table 2 indicated a significant difference in the score on the cloze tests between the familiar text and the unfamiliar text, $t(52)=16.46, p<.001$. The results also showed a significant difference in the reading time between the two texts, $t(52)=-2.07, p<.05)$. Based on the results, two of the research questions and the hypotheses can be addressed below.

Research Question \#1: Does reading a culturally familiar text vs. reading a culturally unfamiliar text influence the Chinese reading comprehension of college students in Taiwan?

Null Hypothesis

There are no differences in the reading comprehension between a culturally familiar text and a culturally unfamiliar text.

Result

The null hypothesis is rejected. That is, readers' degree of familiarity with a reading text affects their reading comprehension performance.

Research Question \#2: Is the reading time affected by readers' familiarity with the text content?

Null Hypothesis

There are no differences in reading time as a function of readers' familiarity with the text content.

Result

The null hypothesis is rejected. That is, readers' familiarity with the text content affects the reading time spent on the text.

Table 3 shows the number of positive and negative answers for each of the six statements on the survey, as well as the results of the chi-square test. Table 3 shows that the number of responses at the two levels was not equally distributed for each statement in the questionnaire. The participants agreed that background knowledge played a significant role in their reading comprehension process and it facilitated comprehension of the reading texts. They also thought that they spent more time reading the unfamiliar text than the familiar one. 
Table 1: Descriptive Statistics for Cloze Test and Reading Time

\begin{tabular}{|l|c|c|c|}
\hline & $N$ & $M$ & $S D$ \\
\hline Cloze test—familiar & 53 & 79.62 & 14.51 \\
\hline Cloze test—unfamiliar & 53 & 43.49 & 19.82 \\
\hline Reading time (in seconds)—familiar & 53 & 262.36 & 146.08 \\
\hline Reading time (in seconds)—unfamiliar & 53 & 300.19 & 114.68 \\
\hline
\end{tabular}

Table 2: Paired-Samples $t$-test for Differences in Mean Comprehension Scores and Reading Time between Familiar and Unfamiliar Texts

\begin{tabular}{|l|c|c|c|c|c|}
\hline & Mean Difference & $S D$ & $t$ & $d . f$. & $p$ \\
\hline Cloze test & 36.13 & 15.98 & 16.46 & 52 & .000 \\
\hline Reading time & -37.83 & 133.19 & -2.07 & 52 & .044 \\
\hline
\end{tabular}

Table 3: Results of the Attitude Survey

\begin{tabular}{|c|c|c|c|c|c|}
\hline Question & Response & $N$ & $x^{2}$ & d.f. & $p$ \\
\hline \multirow{2}{*}{$\begin{array}{l}\text { 1. Is it more difficult for you to comprehend/recall a Chinese text } \\
\text { when you are reading it without appropriate background knowledge? }\end{array}$} & Yes & 46 & \multirow[t]{2}{*}{28.70} & \multirow[t]{2}{*}{1} & \multirow[t]{2}{*}{.000} \\
\hline & No & 7 & & & \\
\hline \multirow{2}{*}{$\begin{array}{l}\text { 2. Do you usually take longer time to read a Chinese text about } \\
\text { which you have very little background knowledge? }\end{array}$} & Yes & 49 & \multirow[t]{2}{*}{38.21} & \multirow[t]{2}{*}{1} & \multirow[t]{2}{*}{.000} \\
\hline & No & 4 & & & \\
\hline \multirow{2}{*}{$\begin{array}{l}\text { 3. Did you anticipate what the text was about when you were } \\
\text { reading the Dragon Boat Festival? }\end{array}$} & Yes & 47 & \multirow[t]{2}{*}{31.72} & \multirow[t]{2}{*}{1} & \multirow[t]{2}{*}{.000} \\
\hline & No & 6 & & & \\
\hline \multirow{2}{*}{$\begin{array}{l}\text { 4. Did you relate what you had known about the holiday to the } \\
\text { reading process when you were reading the Dragon Boat Festival? }\end{array}$} & Yes & 52 & \multirow[t]{2}{*}{49.08} & \multirow[t]{2}{*}{1} & \multirow[t]{2}{*}{.000} \\
\hline & No & 1 & & & \\
\hline \multirow{2}{*}{$\begin{array}{l}\text { 5. Is it easier for you to understand the Dragon Boat Festival than } \\
\text { the St. Patrick's Day in terms of the content? }\end{array}$} & Yes & 52 & \multirow[t]{2}{*}{49.08} & \multirow[t]{2}{*}{1} & \multirow[t]{2}{*}{.000} \\
\hline & No & 1 & & & \\
\hline \multirow{2}{*}{$\begin{array}{l}\text { 6. Do you think you read the Dragon Boat Festival faster than the } \\
\text { St. Patrick's Day? }\end{array}$} & Yes & 45 & \multirow[t]{2}{*}{25.83} & \multirow[t]{2}{*}{1} & \multirow[t]{2}{*}{.000} \\
\hline & No & 8 & & & \\
\hline
\end{tabular}

\section{DISCUSSION}

The findings of this study are worthy of further discussions. First, familiarity with a reading text did affect the participants' reading comprehension performance. It has been shown in the review of the current scholarly literature that when a reader and a writer share cultural assumptions, there is a higher level of interaction between the reader and the text than when such assumptions are not shared (Carrell, 1983, 1987; Carrell \& Eisterhold, 1983; Johnson, 1981, 1982; Smith, 2004). The participants who had the relevant background knowledge of the popular Chinese traditional holiday or who were able to relate what they had already known about the holiday to the reading text performed much better on the cloze test by a significant mean difference of 36.13 . The findings are consistent with the schema-theoretic perspectives on reading comprehension that input is overlaid upon an individual's preexisting knowledge of the world in order to find a match.

Second, the analysis of data collected also indicated that the participants read the culturally familiar text faster than the unfamiliar one. The finding lends support to the results of previous studies (Smith, 2004; Steffensen, et al, 1979). The participants took a mean time period of 262.36 seconds to read the familiar text while they needed to spend about 38 more seconds on the unfamiliar text. The activation of background knowledge or prior knowledge to make sense out of a text is known as top-down processing. The use of top-down processing enables a reader to make inferences or predictions about the incoming written information that is implicitly stated in the text, and thus this conceptually-driven approach facilitates the process of reading comprehension. This explains why the participants read faster the passage related to their own cultural norms. 
Third, the results of the experimental manipulation corroborate the finding that background knowledge plays a critical role in the reading comprehension process because comprehending a text is not simply a task that requires an association of one's linguistic knowledge with the written text. Rather, reading is an interactive process that involves the reader and the text. From the perspective of cognitive psychology, the reader is viewed as an active processor of linguistic input when it comes to the reading comprehension process. Results of the attitude survey also substantiated the claim that most participants relied on their background knowledge in the reading tasks so as to read a passage in a faster and more efficient way.

\section{CONCLUSION AND IMPLICATIONS}

This study examined the effects of culture-specific background knowledge on the Chinese reading comprehension of college students in Taiwan. Based on the results of this study, we may conclude that familiarity with a reading text does affect Taiwanese college students' reading comprehension, recall and reading time. Texts that are consonant with the readers' native culture are better comprehended or remembered than those that are not. Reading comprehension is not simply a task that requires an association of one's linguistic knowledge with the written text, but it also requires the ability to relate the texts to one's knowledge of the world. The results support the schema theory that a reader's background knowledge impacts memory, reading comprehension, interpretation and reading rate.

The results of this study have some implications for classroom teachers and researchers. First, background knowledge plays a vital role in the reading comprehension process. In order to enable the students to connect their knowledge of the world to the reading text, language teachers need to take the component of background knowledge into consideration when they are selecting reading materials. Moreover, language teachers are encouraged to provide reading activities to compensate for the lack of appropriate cultural schemata when culturally unfamiliar reading texts are presented in the language classroom. Providing background knowledge is one feasible possibility with the advantage of entailing much less labor on the teacher's part to increase students' comprehension, and of course it will greatly facilitate students' reading accomplishment. Second, the comprehension process may be very different when readers are processing materials written in their native language and in a second language, and comprehension assessment type could also affect the evaluation of the reading comprehension. Thus, future studies could be done to compare the effects of cultural background knowledge on the reading comprehension, recall and reading time of the first and second language readers and to include two or different assessment measures to provide a more reliable basis for evaluation of reading comprehension.

\section{AUTHOR INFORMATION}

Dr. Chen-Hong Li (corresponding author) is an Assistant Professor in the Department of Applied Foreign Languages at National Penghu University of Science and Technology, Taiwan. He received his B.A. in English from National Chengchi University, M.A. in Linguistics from University of Wisconsin-Madison, and Ph.D. in English with concentration in Composition \& TESOL from Indiana University of Pennsylvania, U.S.A. His research interests include ESL/EFL education, L2 listening/reading assessment, and computer-assisted language teaching and learning. Mailing address: Department of Applied Foreign Languages, National Penghu University of Science and Technology, No. 300 Liu-He Rd., Makung, Penghu 88046, Taiwan. E-mail: chenhong813@gmail.com. Corresponding author.

Dr. Shu-Fen Lai is an Associate Professor and the Chair in the Department of Applied English, and she also serves as the Director of Foreign Language Center at De Lin Institute of Technology, Taiwan. She received her Ph.D. in English with specialization in Composition \& TESOL from Indiana University of Pennsylvania, U.S.A. Her research interests include EFL/ESL reading education and L2 literacy and technology. E-mail: fen1012@hotmail.com. 


\section{REFERENCES}

1. Alptekin, C. (2006). Cultural familiarity in inferential and literal comprehension in L2 reading. System, 34, 494-508.

2. $\quad$ Anderson, N. J. (1999). Exploring second language reading. Boston, MA: Heinle \& Heinle.

3. $\quad$ Baddeley, A. (1997). Human memory. Hillsdale, NJ: Lawrence Erlbaum.

4. Bernhardt, E. B. (1991). Reading development in a foreign language. Norwood, NJ: Ablex.

5. Brantmeier, C. (2004). Building a comprehensive theory of adult foreign language reading: A variety of variables and research methods. The Southern Journal of Linguistics, 27, 1-7.

6. Carrell, P. L. (1983). Three components of background knowledge in reading comprehension. Language Learning, 33, 183-207.

7. Carrell, P. L. (1987). Content and formal schemata in ESL reading. TESOL Quarterly, 21, 461-481.

8. Carrell, P. L. (1988). SLA and classroom instruction: Reading. Annual Review of Applied Linguistics, 9, 223-242.

9. Carrell, P. L., \& Eisterhold, J. C. (1983). Schema theory and ESL reading pedagogy. TESOL Quarterly, 17(4), 553-573.

10. Ellis, N. C. (2001). Memory for language. In P. Robinson (Ed.), Cognition and second language instruction (pp. 33-68). Cambridge: Cambridge University Press.

11. Erten, I. H., \& Razi, S. (2009). The effect of cultural familiarity on reading comprehension. Reading in a Foreign Language, 21(1), 61-77.

12. Eskey, D. E. (1973). A model program for teaching advanced reading to students of English as a Foreign Language. Language Learning, 23, 169-184.

13. Grabe, W. (1991). Current development in second language reading research. TESOL Quarterly, 25, 375406.

14. Harmer, J. (2001). The practice of English language teaching. Essex: Pearson Education Limited.

15. Hewett, N. M. (1985). Reading, cognitive style, and culture: A look at some relationships in second language acquisition. In A. Labarca \& L. M. Bailey (Eds.), Issues in L2: Theory as practice/practice as theory (pp. 62-87). New York: Cambridge University Press.

16. Johnson, P. (1981). Effects on reading comprehension of language complexity and cultural background of a text. TESOL Quarterly, 15, 169-181.

17. Johnson, P. (1982). Effects on reading comprehension of building background knowledge. TESOL Quarterly, 16, 503-516.

18. Ketchum E. M. (2006). The cultural baggage of second language reading: An approach to understanding. Foreign Language Annals, 39, 22-42.

19. Kintsch, W., \& Greene, E. (1978). The role of culture-specific schemata in the comprehension and recall of stories. Discourse Processes, 1, 1-13.

20. McLaughlin, B., Rossman, T., \& McLeod, B. (1983). Second language learning: An informationprocessing perspective. Language Learning, 33, 135-158.

21. Meyer, B. J. F., Talbot, A. P., \& Florencio, D. F. (1999). Reading rate and prose retrieval. Science Studies of Reading, 3, 303-329.

22. Nassaji, H. (2002). Schema theory and knowledge-based processes in second language reading comprehension: A need for alternative perspectives. Language Learning, 52, 439-481.

23. Pulido, D. (2003). Modeling the role of second language proficiency and topic familiarity in second language incidental vocabulary acquisition through reading. Language Learning, 53, 233-284.

24. Pritchard, R. (1990). The effects of cultural schemata on reading processing strategies. Reading Research Quarterly, 25, 273-293.

25. Rumelhart, D. (1980). Schemata: The building blocks of cognition. In R. J. Spiro, B. C. Bruce, \& W. E. Brewer (Eds.), Theoretical issues in reading comprehension (pp. 33-58). Hillsdale, NJ: Erlbaum.

26. Schulz, R. A. (1984). Second language reading research: From theory to practice. Foreign Language Annuals, 17, 309-312.

27. Smith, F. (2004). Understanding reading (6 $6^{\text {th }}$ ed.). Hillsdale, NJ: Erlbaum.

28. Steffensen, M. S., Joag-dev, C., \& Anderson, R. C. (1979). A cross-cultural perspective on reading comprehension. Reading Research Quarterly, 15, 10-29.

29. Yule, G. (1996). Pragmatics. Oxford: Oxford University Press. 